\title{
Characterization of the type III capsular polysaccharide produced by Burkholderia pseudomallei
}

\author{
Shauna L. Reckseidler-Zenteno, ${ }^{1,2}$ Duber-Frey Viteri, ${ }^{1}$ Richard Moore, ${ }^{1}$ \\ Erica Wong, ${ }^{1}$ Apichai Tuanyok ${ }^{1}$ and Donald E. Woods ${ }^{1}$ \\ ${ }^{1}$ Department of Microbiology and Infectious Diseases, University of Calgary Health Sciences \\ Center, Calgary, AB T2N 4N1, Canada \\ ${ }^{2}$ Centre for Science, Athabasca University, Athabasca, AB T9S 979, Canada
}

\begin{abstract}
Burkholderia pseudomallei has been shown to produce more than one capsular polysaccharide (CPS). Analysis of the B. pseudomallei genome has revealed that the organism contains four CPS operons (I-IV). One of these operons (CPS III) was selected for further study. Comparative sequencing analysis revealed that the genes encoding CPS III are present in B. pseudomallei and Burkholderia thailandensis but not in Burkholderia mallei. In this study, CPS III was not found to contribute to the virulence of $B$. pseudomallei. Strains containing mutations in CPS III had the same $\mathrm{LD}_{50}$ value as the wild-type when tested in an animal infection model. Production of CPS III was shown to be induced in water but inhibited in $30 \%$ normal human serum using a lux reporter fusion assay. Microarray analysis of capsule gene expression in infected hamsters revealed that the genes encoding CPS III were not significantly expressed in vivo compared with the genes encoding the previously characterized mannoheptose capsule (CPS I), which is an important virulence factor in B. pseudomallei. Glycosyl-composition analysis by combined GC/MS indicated that the CPS III genes are involved in the synthesis of a capsule composed of galactose, glucose, mannose and xylose.
\end{abstract}

Received 16 May 2010

Accepted 12 August 2010

\section{INTRODUCTION}

Burkholderia pseudomallei is a Gram-negative bacillus and environmental saprophyte found in soil and stagnant waters in a number of regions around the world, particularly in areas that fall between $20^{\circ} \mathrm{N}$ and $20^{\circ} \mathrm{S}$ of the equator (Dance, 1991; Leelarasamee \& Bovornkitti, 1989). The incidence of infection by this organism tends to increase during the rainy season when the water table rises, which results in the presence of more organisms at the surface (Currie \& Jacups, 2003; Currie et al., 2000a, 2004). Infection by $B$. pseudomallei is a result of either direct inoculation into wounds or inhalation of contaminated material (Leelarasamee \& Bovornkitti, 1989). B. pseudomallei is the causative agent of melioidosis, a disease known as 'the great mimicker' because of its similarity to other infections and the difficulty in its diagnosis (Whitmore \& Krishnaswami, 1912; Yee et al., 1988). The clinical manifestations of melioidosis are wide, ranging from acute pneumonia or

Abbreviations: CPS, capsular polysaccharide; $\mathrm{Km}$, kanamycin; NHS, normal human serum; Pm, polymyxin B; RLU, relative light unit; Sm, streptomycin.

Further details of the virulence of the CPS III mutant in a hamster model, and of the glycosyl-composition and glycosyl-linkage analyses, are available as supplementary data with the online version of this paper. acute septicaemia to chronic and latent infections, and the disease has an incubation period that ranges from 2 days to 63 years (Cheng \& Currie, 2005; Ngauy et al., 2005; Sanford, 1995). B. pseudomallei is inherently resistant to a number of antibiotics and, even with aggressive antibiotic therapy, the mortality rate remains high and the incidence of relapse is common (Currie et al., 2000b; White et al., 1989).

Capsules have been shown to contribute to the virulence of many bacterial pathogens (Boulnois \& Roberts, 1990). Previously, our laboratory demonstrated that the capsular polysaccharide (CPS) with the structure [-3)-2-O-acetyl-6deoxy- $\beta$-D-manno-heptopyranose-(1-] was an important virulence determinant of $B$. pseudomallei (Reckseidler et al., 2001). This capsule, which we designated CPS I, was found to be responsible for the survival of $B$. pseudomalle $i$ in the blood of the host by reducing opsonization and phagocytosis (Reckseidler-Zenteno et al., 2005). A mutant in this capsule was also found to be attenuated in a mouse model of melioidosis (Atkins et al., 2002). The same capsule is also produced by Burkholderia mallei and has been shown to be required for virulence in this organism (DeShazer et al., 2001).

Sequence analysis of the completed genome of B. pseudomallei has revealed four operons with the predicted function 
of CPS biosynthesis and export (Holden et al., 2004). One of these operons, CPS I, with the gene identifiers BPSL2786- BPSL2810, corresponds to the previously characterized mannoheptose capsule (Reckseidler et al., 2001; Reckseidler-Zenteno et al., 2005). Three other operons have been identified. One of these operons, with the gene identifiers BPSS0417-BPSS0429, was found to contain genes involved in the biosynthesis of a capsule with gene products that demonstrated homology to those of enteric capsule clusters and LPS biosynthesis operons. We designated this capsule locus CPS II. Another operon, with gene identifiers BPSS1825- BPSS1835, was also found to contain genes with predicted products involved in capsule biosynthesis and was designated CPS III. A fourth operon, CPS IV, with the gene identifiers BPSL2769- BPSL2785, was found to contain genes that may be involved in the synthesis of a capsule.

The objective of this work was to characterize one of these putative capsule operons and to determine the contribution of this capsule to virulence. The role of this capsule operon was recently investigated, but the aim of this study was to enhance the previous literature by performing comparative genomics among Burkholderia species, investigating gene expression patterns and virulence properties, and finally to determine the composition of this capsule (Sarkar-Tyson et al., 2007).

\section{METHODS}

Bacterial strains and growth conditions. The bacterial strains and plasmids used in this study are described in Table 1. B. pseudomallei and Escherichia coli were grown at $37^{\circ} \mathrm{C}$ on Luria-Bertani (LB) broth base (Becton Dickinson) agar plates or in LB broth. For animal studies, B. pseudomallei cultures were grown at $37{ }^{\circ} \mathrm{C}$ in TSBDC (tryptic soy broth dialyzed and chelated) medium (Brett et al., 1997). Where appropriate, antibiotics were added at the following concentrations: $100 \mu \mathrm{g}$ streptomycin $(\mathrm{Sm}) \mathrm{ml}^{-1}, 25 \mu \mathrm{g}$ gentamicin $\mathrm{ml}^{-1}, 25 \mu \mathrm{g}$ kanamycin $(\mathrm{Km}) \mathrm{ml}^{-1}$ and $100 \mu \mathrm{g}$ polymyxin B $(\mathrm{Pm})$ $\mathrm{ml}^{-1}$ for B. pseudomallei, and $100 \mu \mathrm{g}$ ampicillin $\mathrm{ml}^{-1}, 25 \mu \mathrm{g}$ gentamicin $\mathrm{ml}^{-1}$ and 25 and $50 \mu \mathrm{g} \mathrm{Km} \mathrm{ml}{ }^{-1}$ for E. coli.

DNA manipulation. Restriction enzymes and T4 DNA ligase were purchased from Invitrogen Life Technologies and New England Biolabs, and were used according to the manufacturers' instructions. Chromosomal DNA was isolated using a Wizard Genomic DNA purification kit (Promega). Plasmid DNA was isolated using a QIAprep spin miniprep kit (Qiagen). DNA fragments used in cloning procedures were excised from agarose gels and purified using a Qiagen gel extraction kit. PCR products were cloned into pCR2.1TOPO using a TOPO TA cloning kit and chemically competent E. coli TOP10 (Invitrogen Life Technologies) according to the manufacturer's instructions.

Construction of Iux reporter strain B. pseudomallei SZ1829. An internal fragment of the BPSS1829 (bceG) gene was amplified by PCR using primers 1829-int-F and 1829-int-R (Table 2). The DNA fragment was amplified from B. pseudomallei strain 1026b chromosomal DNA via PCR using a Qiagen HotStarTaq master mix kit as described previously (Moore et al., 1999). PCR products were cloned into pCR2.1-TOPO according to the manufacturer's instructions. The $426 \mathrm{bp}$ internal region from BPSS1829 was cloned as an EcoRI fragment into pGSV3-lux, resulting in the plasmid pSZ216 (Table 1).
TOP10(pSZ216) was conjugated with B. pseudomallei strain DD503 in a triparental mating protocol as described previously (Moore et al., 1999; Reckseidler et al., 2001).

Construction of capsule deletion mutants. To construct an inframe deletion of the one of the CPS III genes, oligodeoxyribonucleotide primers were designed to amplify $\sim 600 \mathrm{bp}$ of DNA sequence upstream and downstream of the wabG gene, a predicted glycosyltransferase with the gene identifier BPSS1826 (Table 3). The primers 1826-UP-XbaI and 1826-UP-HindIII (Table 2) were used to amplify the upstream DNA sequence ( $585 \mathrm{bp}$ ) including the ATG start site. The primers 1826-DOWN-HindIII and 1826-DOWN-KpnI were used to amplify a DNA fragment including the stop codon and downstream DNA. The primers 1826-UP-HindIII and 1826DOWN-HindIII were designed to incorporate a unique HindIII restriction site to facilitate cloning of the upstream and downstream fragments to create an in-frame deletion of the $w b p Y$ gene. The primers 1826-UP-XbaI and 1826-DOWN-KpnI were designed to contain $\mathrm{XbaI}$ and $\mathrm{Kp} n \mathrm{I}$ linkers for cloning of the DNA fragments into the plasmids pBluescript SK and pKAS46 (Table 1). The DNA fragments were amplified from B. pseudomallei 1026b chromosomal DNA via PCR using a Qiagen HotStarTaq master mix kit as described previously (Reckseidler-Zenteno et al., 2005) and cloned into pBluescript SK (Table 1). The assembled in-frame deletion was then cloned as an $\mathrm{XbaI} / K p n \mathrm{I}$ fragment into pKAS46, an allelic-exchange vector based on $r p s L$, for counterselection, resulting in the plasmid pKAS46 1826 (Table 1). B. pseudomallei DD503 was the recipient strain used for allelic exchange (Table 1). Allelic exchange was performed as described previously, except that transconjugants were plated on $\mathrm{Pm}$ and $\mathrm{Km}$ (Moore et al., 1999). The $\mathrm{Pm}^{\mathrm{r}} \mathrm{Km}^{\mathrm{r}}$ transconjugants were subsequently transferred to plates containing Sm to select for the loss of pKAS46. $\mathrm{Sm}^{\mathrm{r}} \mathrm{Km}^{\mathrm{s}}$ transconjugants were screened by PCR for the in-frame deletion using the primers 1826UP-XbaI and 1826-DOWN-KpnI. The mutant strain B. pseudomallei $\operatorname{DD} 503(\Delta 1826)$ contained the expected deletion in the $w a b G$ gene relative to wild-type $1026 \mathrm{~b}$.

A multiple deletion strain containing mutations in three of the characterized or predicted capsule operons (CPS I, II and IV) was constructed in order to create a strain that produced only CPS III. Deletions in one of the genes from the CPS II and IV operons were constructed as described above using the primers 418-UP-XbaI, 418UP-HindIII, 418-DOWN-HindIII and 418-DOWN-KpnI to construct a deletion in the CPS II operon, and with the primers 2780-UP-XbaI, 2780-UP-HindIII, 2780-DOWN-HindIII and 2780-DOWN-KpnI to construct a deletion in the CPS IV operon (Table 2), resulting in the strains DD503 $(\Delta 418)$ and DD503 $(\Delta 2780)$ (Table 1). A CPS I deletion was constructed previously to create B. pseudomallei SZ210 (Table 1). SZ210, containing an in-frame deletion in the $w c b B$ gene and deficient in CPS I production was used instead of DD503 for construction of the capsule triple-mutant strain. Plasmid pKAS46 4418 was conjugated with SZ210 resulting in $\operatorname{SZ210}(\Delta 418)$, and plasmid pKAS46 2780 was conjugated with $\operatorname{SZ210}(\Delta 418)$ resulting in SZ210 $(\Delta 418)(\Delta 2780)$, a strain harbouring mutations in the CPS I, II and IV operons (Table 1). All deletions were confirmed by PCR as described above using the upstream and downstream primers for each gene of interest.

Animal studies. The animal model of acute B. pseudomallei infection has been described previously (DeShazer \& Woods, 1999). To assess the virulence of the capsule mutant strain SZ1829 compared with wild-type B. pseudomallei 1026b, female Syrian hamsters aged 6-8 weeks (five per group) were inoculated intraperitoneally with $10^{1}, 10^{2}$ or $10^{3}$ c.f.u. The control group (five hamsters) infected with wild-type $1026 \mathrm{~b}$ were inoculated with $10^{1}$ c.f.u. At $48 \mathrm{~h}$, the numbers of hamsters that had succumbed were recorded, and the blood of infected animals was serially diluted and plated for bacterial quantification. 
Table 1. Bacterial strains and plasmids used in this study

\begin{tabular}{|c|c|c|}
\hline Strain/plasmid & Description & Reference/source \\
\hline \multicolumn{3}{|l|}{ Strains } \\
\hline \multicolumn{3}{|l|}{ E. coli } \\
\hline \multirow[t]{2}{*}{ DH10B } & $\mathrm{F}^{-} m c r A \Delta(m r r-h s d R M S-m c r B C) \varphi 80 l a c Z \Delta \mathrm{M} 15$ & Invitrogen \\
\hline & $\begin{array}{l}\Delta \text { lacX74 deoR recA1 endA1 ara } \Delta 139 \Delta(\text { ara-leu }) ; 7697 \text { galU galK } \lambda^{-} \text {rpsL } \\
\text { nupG } \lambda^{-} \text {tonA }\end{array}$ & \\
\hline HB101 & $\begin{array}{l}\mathrm{F}^{-} \Delta(\text { gpt-proA }) 62 \text { leu supE44 ara14 galK2 lacY1; } \Delta(\text { mcrC-mrr }) \text { rpsL20 }\left(\mathrm{Sm}^{\mathrm{r}}\right) \\
x y l-5 \text { mtl-1 recA13 }\end{array}$ & Boyer \& Roulland-Dussoix (1969) \\
\hline S17-12pir & $\mathrm{Tp}^{\mathrm{r}} \mathrm{Sm}^{\mathrm{r}}$ recA, thi, pro, hsdR-M ${ }^{+} \mathrm{RP} 4: 2-\mathrm{Tc}: \mathrm{Mu}: \mathrm{Km} \operatorname{Tn} 7 \lambda$ pir & Biomedal Life Science \\
\hline \multicolumn{3}{|l|}{ B. pseudomallei } \\
\hline $1026 \mathrm{~b}$ & Clinical isolate; $\mathrm{Km}^{\mathrm{r}} \mathrm{Gm}^{\mathrm{r}} \mathrm{Sm}^{\mathrm{r}} \mathrm{Pm}^{\mathrm{r}} \mathrm{Tc}^{\mathrm{s}} \mathrm{Tp}^{\mathrm{s}}$ & DeShazer et al. (1997) \\
\hline DD503 & $\begin{array}{l}\text { 1026b derivative; allelic exchange strain; } \Delta(\operatorname{amrR}-o p r A)\left(\mathrm{Km}^{\mathrm{s}} \mathrm{Gm}^{\mathrm{s}} \mathrm{Sm}^{\mathrm{s}}\right) \\
r p s L\left(\mathrm{Sm}^{\mathrm{r}}\right)\end{array}$ & Moore et al. (1999) \\
\hline SZ1829 & DD503 derivative; (pSZ216); $\mathrm{Gm}^{\mathrm{r}}$ & This study \\
\hline $\operatorname{DD} 503(\Delta 418)$ & DD503 derivative; (pKAS46 $\Delta 418) ; \Delta k p s E$ & This study \\
\hline $\operatorname{DD} 503(\Delta 1826)$ & DD503 derivative; (pKAS46 $\Delta 1826) ; \Delta w a b G$ & This study \\
\hline $\operatorname{DD} 503(\Delta 2780)$ & DD503 derivative; (pKAS46 $\Delta 2780) ; \Delta w z a$ & This study \\
\hline $\operatorname{SZ210}(\Delta 418)$ & SZ210 derivative; (pKAS46 $\Delta 418) ; \Delta w c b B, \Delta k p s E$ & This study \\
\hline $\operatorname{SZ210}(\Delta 418)(\Delta 2780)$ & SZ210 derivative; (pKAS46 $\Delta 418),(\mathrm{pKAS} 46 \Delta 2780) ; \Delta w c b B, \Delta k p s E, \Delta w z a$ & This study \\
\hline \multicolumn{3}{|l|}{ B. thailandensis } \\
\hline E264 & Soil isolate; $\mathrm{Km}^{\mathrm{r}} \mathrm{Gm}^{\mathrm{r}} \mathrm{Sm}^{\mathrm{r}} \mathrm{Pm}^{\mathrm{r}} \mathrm{Tc}^{\mathrm{s}} \mathrm{Tp}^{\mathrm{s}}$ & Brett et al. (1998) \\
\hline \multicolumn{3}{|l|}{ Plasmids } \\
\hline pGSV3-lux & Mobilizable suicide vector containing lux operon from P. luminescens; OriT; $\mathrm{Gm}^{\mathrm{r}}$ & Moore et al. (2004) \\
\hline pCR2.1-TOPO & Topoisomerase-mediated cloning vector; $\mathrm{Ap}^{\mathrm{r}} \mathrm{Km}^{\mathrm{r}}$ & Invitrogen \\
\hline pKAS46 $\Delta 1826$ & $\begin{array}{l}\text { In-frame deletion of CPS III } w a b G \text { gene cloned as an XbaI-KpnI } \\
\text { fragment into pKAS46; } \mathrm{Ap}^{\mathrm{r}} \mathrm{Km}^{\mathrm{r}}\end{array}$ & This study \\
\hline pKAS46 2780 & $\begin{array}{l}\text { In-frame deletion of CPS IV } w z a \text { gene cloned as an XbaI-KpnI } \\
\text { fragment into pKAS46; } \mathrm{Ap}^{\mathrm{r}} \mathrm{Km}^{\mathrm{r}}\end{array}$ & This study \\
\hline
\end{tabular}

Ap, Ampicillin; Gm, gentamicin; Tc, tetracycline; Tp, trimethoprim.

Western blot analysis of capsule production. Whole-cell extracts of $B$. pseudomallei strains for Western blot analysis were prepared as described previously (Bryan et al., 1994). Immunoassay was performed with a 1:500 dilution of the primary antibody, mouse mAb 147 raised against B. pseudomallei CPS (Reckseidler-Zenteno et al., 2005). The secondary antibody used was horseradish peroxidase-conjugated goat anti-mouse polyvalent immunoglobulins (IgA, IgM and IgG; Sigma).

Sequence analysis of capsule clusters. Sequence analysis of the $B$. pseudomallei, B. mallei and Burkholderia thailandensis genomes was performed using the Artemis program (version 7) provided by the Sanger Centre (http://www.sanger.ac.uk/Projects/), the CMR BLAST program through The Institute for Genomic Research (http://www. tigr.org/) and using the BLAST program through the National Center for Biotechnology website (http://www.ncbi.nlm.nih.gov/).

Bioluminescence assay to investigate capsule regulation. Regulation of the B. pseudomallei capsule operons CPS I and III under a number of conditions was performed as described previously (Reckseidler et al., 2001). The lux reporter strains B. pseudomallei SZ211 (CPS I${ }^{-}$) and SZ1829 (CPS $\mathrm{III}^{-}$) were inoculated into LB broth, M9 medium plus $1 \%$ glucose, M9 plus $1 \%$ glucose plus $30 \%$ normal human serum (NHS) or water. Ninety-six-well plates containing $150 \mu \mathrm{l}$ medium were inoculated with $5 \mu \mathrm{l}$ overnight culture of each strain (five replicates per condition) and incubated at $37{ }^{\circ} \mathrm{C}$ with shaking, except for the water samples, which were incubated at $37{ }^{\circ} \mathrm{C}$ without shaking to replicate the condition of 
Table 2. Sequences of the primers used in this study

\begin{tabular}{|c|c|}
\hline Primer & Sequence $\left(5^{\prime} \rightarrow 3^{\prime}\right)$ \\
\hline 1829-int-F & GCTCACGGTGTCGGGCAAGAT \\
\hline 1829-int-R & GCTCAACACGACATGCACGAG \\
\hline 1826-UP-XbaI & GGGTCTAGAGCTTCATCTCGTTCTGTCTGT \\
\hline 1826-UP-HindIII & GATAAGCTTTGACGATGGCGATTCTCACTG \\
\hline 1826-DOWN-HindIII & GCGAAGCTTTGACGCAGGAGCGGTCGTAAT \\
\hline 1826-DOWN-KpnI & GCGGGTACCCAGATCGAATTGCGCGGTGTC \\
\hline 418-UP-XbaI & GGGTCTAGACCGCGCAGCAGGCGCAACT \\
\hline 418-UP-HindIII & GATAAGCTTGACGATGCGCGCGATCAG \\
\hline 418-DOWN-HindIII & GCGAAGCTTGTCATCGGCAGGGCGTT \\
\hline 418-DOWN-KpnI & GCGGGTACCTATCGAGCACGCCGAAGC \\
\hline 2780-UP-XbaI & GGGTCTAGATCCGTTCAAGTGCCTGAAGT \\
\hline 2780-UP-HindIII & GATAAGCTTACTACCCATCCACACСТCTAT \\
\hline 2780-DOWN-HindIII & GCGAAGCTTGTGACCAAATGATCGAATCGA \\
\hline 2780-DOWN-KpnI & GCGGGTACCTATGGGGTCTTGGAGATTC \\
\hline
\end{tabular}

stagnant water. Optical density readings $\left(\mathrm{OD}_{540}\right)$ and luminescence measurements [in relative light units (RLU)] were taken every hour. The $\mathrm{OD}_{540}$ values of the bacterial cultures were measured using a Bio-Rad microplate reader and Microplate Manager version 5.1 software (Bio-Rad). Luminescence was measured with a reporter microplate luminometer and reporter software (Turner Biosystems). Luminescence/absorbance was calculated to determine the level of gene expression for each strain and a difference in expression greater than 2.5 -fold was considered significant.

Microarray analysis of capsule genes in vivo and in vitro. Capsule gene expression in vivo was assessed using a previously described low-density DNA oligo-microarray (Moore et al., 2004; Tuanyok et al., 2005). Total RNA was isolated from the lungs and livers of B. pseudomallei-infected hamsters at $40 \mathrm{~h}$ and from $B$. pseudomallei grown in LB broth. For the in vivo data, five hamsters were injected with 100 c.f.u. B. pseudomallei 1026b. Serial dilutions and plate counts were used to confirm the dose. All hamsters were severely ill at $40 \mathrm{~h}$ after the inoculation. This time point was chosen based on previous data generated from our laboratory indicating that the bacterial loads in the liver and lungs at $48 \mathrm{~h}$ from an inoculum of 100 c.f.u. is approximately $10^{4}$ c.f.u. $\mathrm{ml}^{-1}$ (Reckseidler-Zenteno et al., 2005). The $40 \mathrm{~h}$ time point was chosen instead of $48 \mathrm{~h}$ to ensure that the animals were still alive but close to death when sacrificed. At this time, all hamsters were euthanized, and the infected lungs and livers were preserved in RNAlater solution (Ambion) at $-70{ }^{\circ} \mathrm{C}$ until required. For the in vitro results, bacterial cells were harvested from $20 \mathrm{ml}$ culture in LB broth at an $\mathrm{OD}_{600}$ 0.9. Prior to the harvesting of the cells, $1 \%(\mathrm{v} / \mathrm{v})$ RNAlater was added to the culture, which was maintained at $4{ }^{\circ} \mathrm{C}$. Following total bacterial RNA purification, bacterial mRNA purification was performed from both sources described above using MICROBExpress (Ambion) following the manufacturer's instructions. The level of gene expression in vivo was determined by comparing the in vivo and in vitro results. Scanning was performed with a Virtek ChipReader (Virtek Biotech) and the fluorescence signals from both dyes were quantified using QuantArray

Table 3. B. pseudomallei CPS III genes, homologous proteins and predicted functions

\begin{tabular}{|c|c|c|c|c|c|c|}
\hline $\begin{array}{l}\text { Gene } \\
\text { identifier }\end{array}$ & Size (bp) & $\begin{array}{c}\text { Homologous } \\
\text { protein }\end{array}$ & Predicted protein function & Identity & Organism & Reference \\
\hline BPSS1825 & 1167 & НерB & Glycosyltransferase & $37 \%$ & Anabaena spp. & Wang et al. (2007) \\
\hline BPSS1826 & 1185 & WabG & Glycosyltransferase & $29 \%$ & Klebsiella pneumoniae & Regué et al. (2005) \\
\hline BPSS1827 & 1476 & CheA & Chemotaxis histidine kinase & $35 \%$ & Pseudomonas fluorescens & de Weert et al. (2002) \\
\hline BPSS1828 & 1140 & Cap1E & Glycosyltransferase & $34 \%$ & Pseudomonas aeruginosa & Raymond et al. (2002) \\
\hline BPSS1829 & 948 & BceG & Glycosyltransferase & $77 \%$ & Burkholderia cepacia & Moreira et al. (2003) \\
\hline BPSS1830 & 2220 & Wzc & $\begin{array}{l}\text { Capsule export, tyrosine- } \\
\text { protein kinase }\end{array}$ & $36 \%$ & Escherichia coli & Grangeasse et al. (2003) \\
\hline BPSS1831 & 1176 & Wza & $\begin{array}{l}\text { Capsule export, outer- } \\
\text { membrane protein }\end{array}$ & $36 \%$ & Escherichia coli & Dong et al. (2006) \\
\hline BPSS1832 & 435 & Wzb & $\begin{array}{l}\text { Transport, tyrosine-protein } \\
\text { phosphatase }\end{array}$ & $40 \%$ & Escherichia coli & Lescop et al. (2006) \\
\hline BPSS1833 & 1422 & RkpK & $\begin{array}{l}\text { UDP-glucose-6- } \\
\text { dehydrogenase }\end{array}$ & $50 \%$ & Rhizobium meliloti & Kereszt et al. (1998) \\
\hline BPSS1834 & 1416 & WcaJ & Sugar transferase & $39 \%$ & Salmonella typhimurium & Stevenson et al. (2000) \\
\hline BPSS1835 & 1461 & ManC & $\begin{array}{l}\text { GDP-mannose- } \\
\text { pyrophosphorylase }\end{array}$ & $48 \%$ & Salmonella enterica & Jensen \& Reeves (2001) \\
\hline
\end{tabular}


microarray analysis software (Packard Bioscience). Normalization and data analysis were performed with GeneTraffic software (Iobion Informatics). Data obtained from at least 24 hybridizations of two independent RNA preparations of each type of infected organ including flip-dye replications were used in each analysis. Normalization of data was performed using LOWESs (locally weighted scatter plot smoother), a curve-fitting algorithm. To select significantly expressed genes, the following were used: differences ( $n$-fold), mean $\log _{2}$ ratio, SD, coefficient of variance and Student's $t$-test. Hierarchical clustering and $\mathrm{K}$-means clustering analyses were performed using The Institute for Genomic Research $\mathrm{MeV}$ software (www.tigr.org/). The data are represented as the in vivo expression divided by the in vitro expression for all of the infected organs combined.

Purification of CPS III. Purification of CPS III was achieved by utilizing a multiple deletion strain containing mutations in the known and predicted capsule operons of B. pseudomallei, except for the CPS III operon. Capsule purification was performed on B. pseudomallei SZ210 $(\Delta 418)(\Delta 2780)$ according to a published hot phenol extraction procedure (Perry et al., 1995; Westphal \& Jann, 1965). The purified capsule was not delipidated.

Glycosyl-composition and glycosyl-linkage analysis of CPS III. Glycosyl-composition analysis was performed on the purified capsule by combined GC/MS. An aliquot of the sample was added to a glass tube with $20 \mu \mathrm{g}$ inositol as the internal standard. Methylglycosides were prepared from the dry sample following mild acid treatment by methanolysis in $1 \mathrm{M} \mathrm{HCl}$ in methanol at $80{ }^{\circ} \mathrm{C}$ for $16 \mathrm{~h}$, followed by re- $N$-acetylation with pyridine and acetic anhydride in methanol (for the detection of amino sugars). The sample was then per-Otrimethylsilylated by treatment with Tri-Sil (Pierce) at $80{ }^{\circ} \mathrm{C}$ for $30 \mathrm{~min}$. These procedures were carried out as described elsewhere (Merkle \& Poppe, 1994; York et al., 1986). GC/MS analysis of the trimethylsilylated methylglycosides was performed on an AT $6890 \mathrm{~N}$ GC interfaced to a 5975B MSD, using a Supelco EC-1 fused silica capillary column $(30 \mathrm{~m} \times 0.25 \mathrm{~mm}$ internal diameter $)$

For glycosyl-linkage analysis, the sample was permethylated, depolymerized, reduced and acetylated. The resulting partially methylated alditol acetates were analysed by GC/MS as described by York et al. (1986).

\section{RESULTS}

\section{B. pseudomallei contains four polysaccharide operons}

Three of the identified capsule operons in the genome of B. pseudomallei were analysed further using the BLAST program and Artemis. The operons are illustrated in Fig. 1. The operon consisting of the genes BPSS0417BPSS0429 was designated CPS II (Fig. 1a). Another operon, BPSS1825-BPSS1835, was designated CPS III and the predicted homologues were investigated further (Fig. 1b, Table 3). A fourth operon, CPS IV, was found to contain genes that may be involved in the synthesis of a capsule, with the gene identifiers BPSL2769-BPSL2785 (Fig. 1c).

\section{Distribution of capsule loci among the three Burkholderia species}

Comparative analysis of the genomes of $B$. pseudomallei, $B$. mallei and $B$. thailandensis was performed to determine whether all of the predicted B. pseudomallei capsule operons were present in B. mallei and B. thailandensis. As shown in Fig. 1, all three capsules were found to be present in $B$. pseudomallei and B. thailandensis but not B. mallei. This is in contrast to CPS I, which is present in B. pseudomallei and B. mallei but not in B. thailandensis (DeShazer et al., 2001; Holden et al., 2004; Reckseidler et al., 2001; ReckseidlerZenteno et al., 2005; Yu et al., 2006). CPS II was found to be identical in B. pseudomallei and B. thailandensis, but $B$. thailandensis was found to contain two flanking hypothetical genes not present in B. pseudomallei (Fig. 1a). The CPS II genes were found to be deleted entirely from $B$. mallei (Fig. 1a). A large chromosomal region ranging from ORFs BPSS0404 to BPSS0491 including CPS II was shown to be deleted in B. mallei compared with B. pseudomallei and was replaced with a large chromosomal region containing ORFs BMAA0555 (IS407A orfB) to BMAA1784, a unique hypothetical protein not found in B. pseudomallei (Fig. 1a). The two genomes aligned with the presence of the alkyl hydroperoxidase reductase genes $a h p C$ and $a h p F$, but these were organized in the opposite orientation in B. mallei compared with B. pseudomallei (Fig. 1a). The entire CPS III operon and flanking genes were shown to be the same in both B. pseudomallei and B. thailandensis (Fig. 1b). In contrast, the majority of the CPS III cluster was deleted from B. mallei with the exception of the wcaJ and manC genes, as well as the two flanking hypothetical genes on one side and another hypothetical gene on the other side of the deleted region (Fig. 1b). The deleted region of the CPS III genes in B. mallei was found to be replaced with the IS407A orf $A$ and orf $B$ genes (Fig. 1b). The entire CPS IV region was found to be replaced in $B$. mallei and flanked by two IS407A elements (Fig. 1c). The ORF BPSL2785, which encodes a hypothetical protein, was present in B. mallei (BMA2284.1) ATCC 23344, as well as in a number of other $B$. mallei strains, but was organized in the opposite orientation. The genomes of $B$. pseudomallei, B. thailandensis and B. mallei all diverged upstream of the CPS IV region, but all three organisms were found to align at the location of the ompA and hypothetical genes (Fig. 1c).

\section{Mutation in CPS III does not affect the production of CPS I}

Western blot analysis of CPS I production was performed using whole-cell extracts of strains containing mutations in the CPS I and III operons to confirm that a disruption in the CPS III cluster had no effect on CPS I production. As shown in Fig. 2, SZ1829, containing a mutation in CPS III, was shown to produce CPS I. This was demonstrated by the reaction to a mAb to CPS $\mathrm{I}$, as indicated by the presence of a $200 \mathrm{kDa}$ band. The reaction of this strain was similar to that of wild-type B. pseudomallei strains $1026 \mathrm{~b}$ and DD503 and was in contrast to that of B. pseudomallei SZ210, which harboured a deletion in the CPS I operon and was deficient in CPS I production. 
(a)

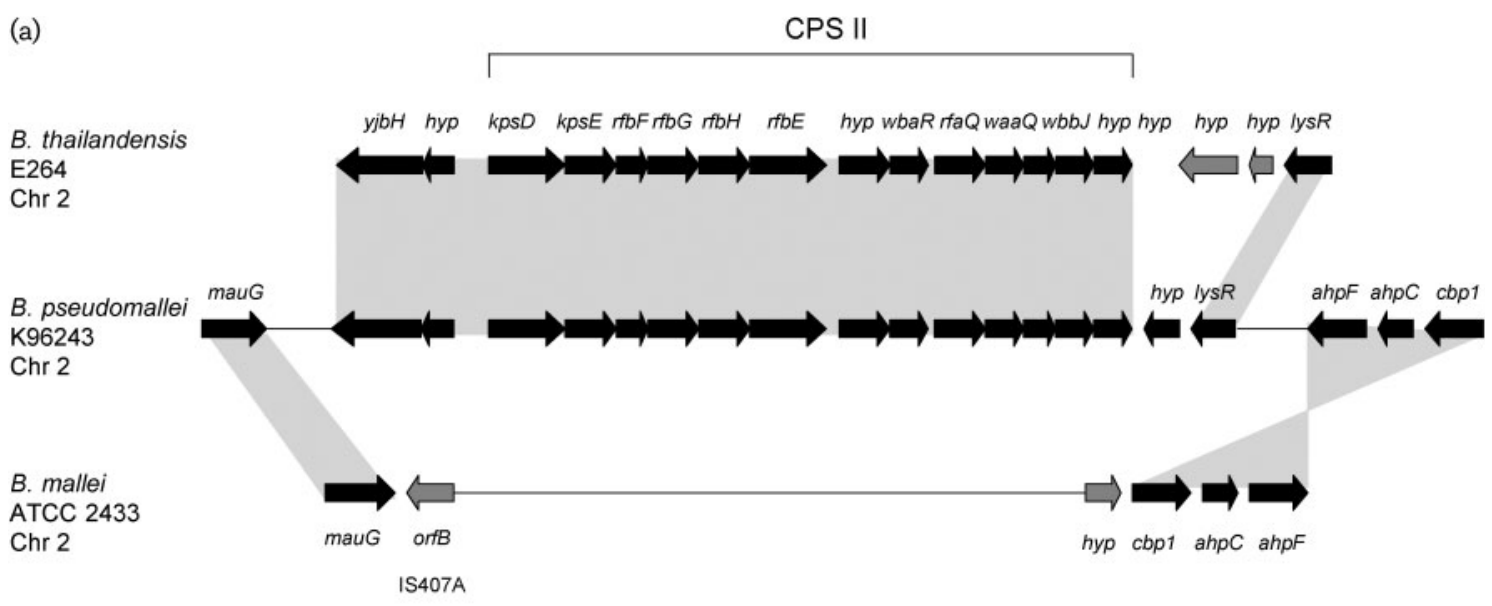

(b)

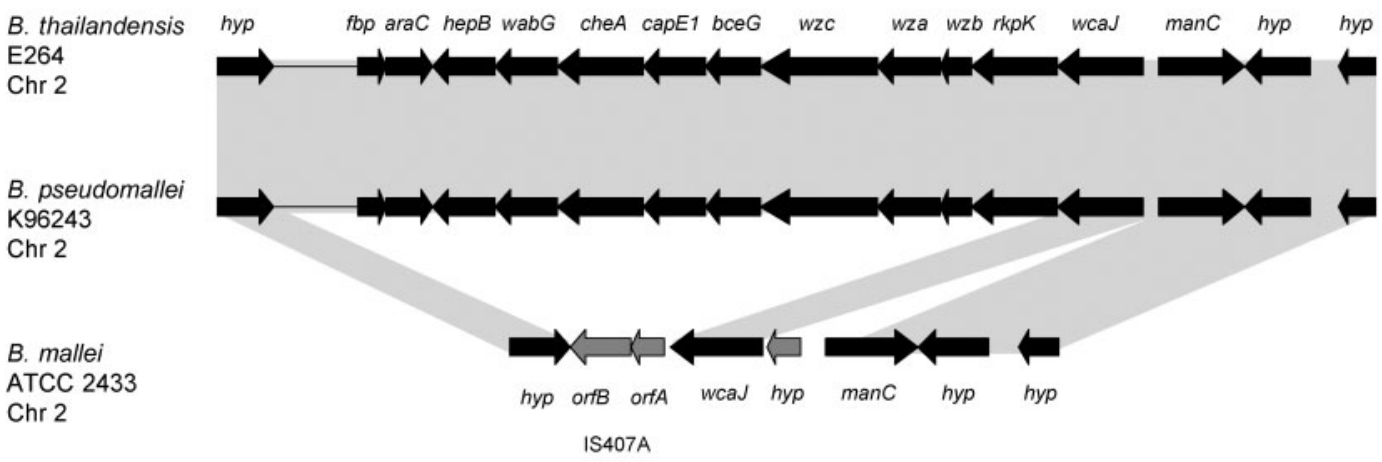

(c)

CPS IV

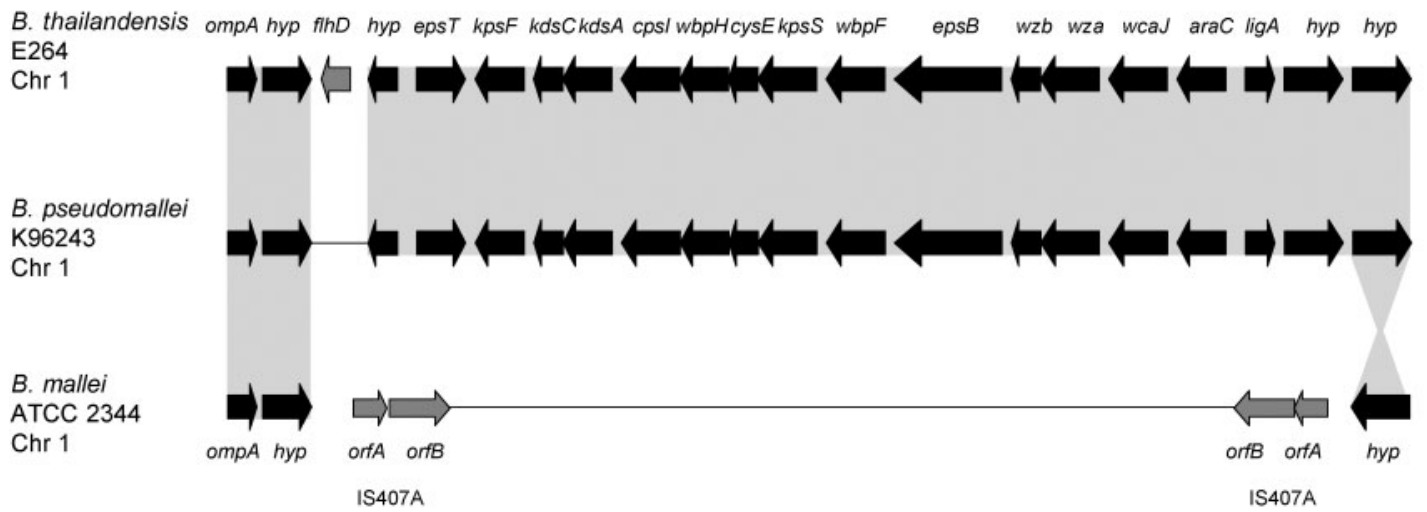

Fig. 1. Organization of the chromosomal regions containing CPS II, III and IV in B. pseudomallei K96243, B. thailandensis E264 and B. mallei ATCC 23344. The capsule operon and the genes involved are indicated in each figure. Gene names are shown according to homologous gene products as determined by the Artemis program and BLAST searches. Arrows indicate the direction of transcription. Genes identical among species are indicated in black and genes unique to a species are indicated in grey. (a) The chromosomal region containing CPS II and flanking DNA in B. pseudomallei, B. thailandensis and B. mallei. This region extends from nt 546190 to 671369 in $B$. pseudomallei, nt 2398500 to 2421308 in $B$. thailandensis and nt 563346 to 1957789 in B. mallei. (b) The chromosomal region containing CPS III and flanking DNA. This region extends from nt 2463970 to 2499713 in B. pseudomallei, nt 643144 to 676838 in B. thailandensis and nt 263152 to 270492 in B. mallei. (c) The chromosomal region containing CPS IV and flanking DNA. This region extends from nt 3184073 to 3199575 in $B$. pseudomallei, nt 1679130 to 1694403 in B. thailandensis and nt 2269377 to 2283058 in B. mallei. hyp, Hypothetical protein gene. 


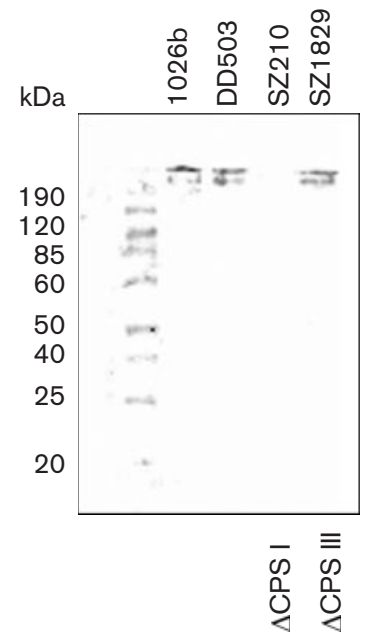

Fig. 2. Western blot analysis of CPS I production in $B$. pseudomallei SZ1829. Whole-cell extracts of wild-type and mutant strains of $B$. pseudomallei were prepared and reacted with a mAb to CPS I. The B. pseudomallei strains 1026b, DD503, SZ210 and SZ1829 are indicated.

\section{CPS III does not contribute to virulence in the Syrian hamster model of melioidosis}

To assess the role of CPS III in virulence, a strain with a mutation in the CPS III operon was tested for virulence compared with wild-type B. pseudomallei in the Syrian hamster model of melioidosis. Syrian golden hamsters were inoculated intraperitoneally with $10^{1}-10^{3}$ cells of wild-type B. pseudomallei 1026b or the capsule mutant SZ1829. After $48 \mathrm{~h}$, the $\mathrm{LD}_{50}$ values were determined. As shown in Table 4 , SZ1829 had $\mathrm{LD}_{50}$ values of $<10$ c.f.u., identical to that of wild-type B. pseudomallei, indicating that this capsule is not required for virulence (see also Supplementary Table S1 available with the online journal). In addition, the bacterial load in the blood of the infected hamsters was similar to that of the wild-type strain, and was significantly higher than that of the non-pathogenic B. thailandensis E264 and the CPS I mutant B. pseudomallei SR1015, both of which are incapable

Table 4. Virulence of the CPS III mutant in the Syrian hamster model of acute melioidosis

\begin{tabular}{|llcc|}
\hline Strain & $\begin{array}{c}\text { CPS cluster } \\
\text { inactivated }\end{array}$ & $\begin{array}{c}\text { LD }_{\mathbf{5 0}} \\
(\text { c.f.u. })^{*}\end{array}$ & $\begin{array}{c}\text { Blood bacterial } \\
\text { count }\left(\text { c.f.u. } \mathbf{~ m l}^{-\mathbf{1}} \text { ) }\right.\end{array}$ \\
\hline 1026b & None & $<10$ & $4.1 \times 10^{5}$ \\
E264 & None & $6.8 \times 10^{5}$ & 0 \\
SR1015 & CPS I & $3.5 \times 10^{5}$ & 3 \\
SZ1829 & CPS III & $<10$ & $1.9 \times 10^{5}$ \\
\hline
\end{tabular}

${ }^{*} \mathrm{LD}_{50}$ values for $1026 \mathrm{~b}, \mathrm{E} 264$ and SR1015 were calculated previously (Brett et al., 1997; Reckseidler et al., 2001). of establishing bacteraemia (Brett et al., 1997; ReckseidlerZenteno et al., 2005). This indicated that CPS III does not contribute to persistence in the blood.

\section{CPS III is not expressed in NHS}

A lux reporter strain was constructed in the CPS III operon by cloning an internal fragment of one of the genes into pGSV3-lux, a suicide vector containing a promoterless lux operon from Photorhabdus luminescens (Table 1). Regulation of this capsule in an environment similar to that encountered in the host was determined by growing the lux reporter strain SZ1829 in the presence of M9 plus $1 \%$ glucose versus M9 plus $1 \%$ glucose plus $30 \%$ NHS (Fig. 3). The $\mathrm{OD}_{540}$ values and luminescence measurements were determined every hour. As shown in Fig. 3(b), expression of CPS III (SZ1829) was higher in M9 plus 1\% glucose alone compared with M9 plus $1 \%$ glucose plus $30 \%$ NHS. The expression of SZ1829 was threefold to fourfold lower in $30 \%$ NHS. This was in contrast to the expression of CPS I (SZ211), which was significantly more highly expressed in $30 \%$ NHS at a level of threefold to fourfold compared with growth in M9 plus $1 \%$ glucose alone (Fig. 3a). Although CPS III demonstrated higher expression initially in $30 \%$ NHS, this may have been due to the fact that the addition of NHS caused precipitation in the medium, which affected the OD of the cultures.

\section{CPS III is expressed in water}

Expression of the lux operon in reporter strains SZ211 $\left(\mathrm{CPS} \mathrm{I}^{-}\right)$and SZ1829 $\left(\mathrm{CPS} \mathrm{III}^{-}\right.$) was also measured in water to determine whether CPS III was induced in this environment. Overnight cultures of SZ211 and SZ1829 were inoculated into sterile water and incubated at $37{ }^{\circ} \mathrm{C}$ without shaking. Capsule expression was determined as described above, but the luminescence/absorbance calculations for water were compared with the values for these strains when grown in LB broth. CPS III was found to be induced in water compared with LB broth (Fig. 4b). The expression of SZ1829 was found to be significant, with an increase of twofold to threefold over the course of the experiment (Fig. 4b). The expression of CPS I was found to be more than fourfold higher in LB broth compared with water (Fig. 4a).

\section{Microarray analysis of CPS III expression in vivo}

Microarray analysis of capsule expression was performed using a low-density DNA microarray. RNA was isolated from the livers and lungs of hamsters infected with $B$. pseudomallei and from B. pseudomallei grown in LB broth. The results of the microarray experiment are shown in Table 5. The level of gene expression, or fold change, is represented as the ratio of gene expression in the hamster compared with growth in LB broth. As shown in Table 5, CPS III genes were not found to be significantly expressed in vivo, as most of the fold changes 


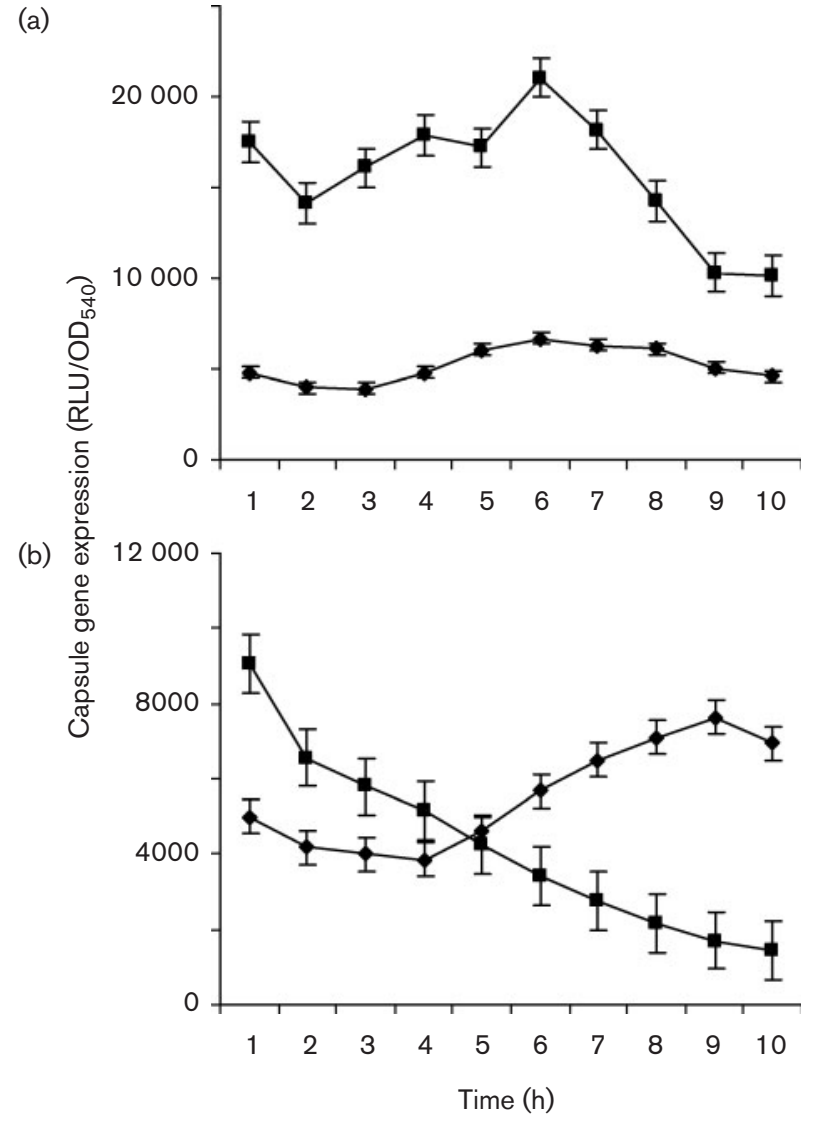

Fig. 3. Expression of B. pseudomallei capsules CPS I and III in the presence of $30 \%$ NHS. B. pseudomallei lux reporter strains SZ211 (a) and SZ1829 (b) were grown in M9 plus $1 \%$ glucose or in M9 plus $1 \%$ glucose plus $30 \% \mathrm{NHS}$ at $37{ }^{\circ} \mathrm{C}$ with shaking. The $\mathrm{OD}_{540}$ and luminescence (RLU) were measured at each time point. Capsule expression was determined by normalizing light production against growth $\left(\mathrm{RLU} / \mathrm{OD}_{540}\right)$ of each strain for each time point. The data represent the mean $\pm \mathrm{SD}$ of lux reporter activity normalized for growth (five replicates per experiment) from three separate experiments. $\downarrow$, M9+glucose; $\mathbf{\square}, \mathrm{M} 9+\mathrm{NHS}$.

were determined to be less than twofold. Many of the genes had negative fold change values, indicating that these genes are suppressed in the host environment. The highest fold change result was 2.337866 for BPSS1827, a predicted glucose-6-phosphate isomerase, which was still much lower than the fold changes observed for CPS I genes, which were significantly higher (Tuanyok et al., 2006).

\section{Carbohydrate composition of CPS III}

Glycosyl-composition analysis was performed on the purified capsule by combined GC/MS. The results indicated that CPS III is composed of galactose, glucose, mannose, xylose and rhamnose residues, with the highest proportion of carbohydrate being galactose and glucose (Table 6). Glycosyl-linkage

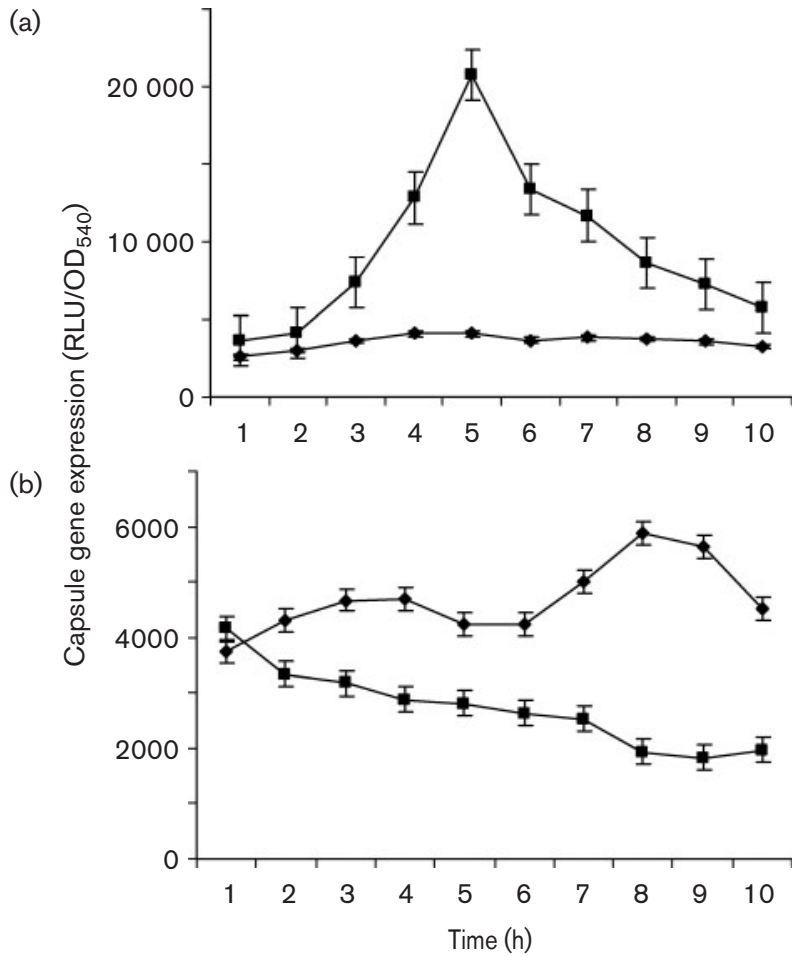

Fig. 4. Expression of B. pseudomallei capsules CPS I and III in the presence of water. B. pseudomallei lux reporter strains SZ211 (a) and SZ1829 (b) were inoculated into water and incubated at $37{ }^{\circ} \mathrm{C} . \mathrm{OD}_{540}$ and luminescence (RLU) were measured at each time point. Capsule expression was determined by normalizing light production against growth $\left(R L U / O D_{540}\right)$ of each strain for each time point and comparing these results with growth in LB broth. The data represent the mean $\pm \mathrm{SD}$ of lux reporter activity normalized for growth (five replicates per experiment) from three separate experiments. Water; $\mathbf{\square}$, LB broth.

analysis was also performed (Table 7). The predominant glycosyl residue detected was a terminally linked heptopyranosyl at a percentage of 23.2. Other residues detected were a terminally linked and a 4-linked glucopyranosyl at percentages of 14.6 and 10.8, respectively. Supplementary Figs S1 and S2 (available with the online journal) illustrate the polysaccharide peaks for the glycosyl-composition and glycosyl-linkage analysis as determined by GC/MS.

\section{DISCUSSION}

Although significant advances have been made, melioidosis continues to be a public-health concern in many regions of the world (Cheng \& Currie, 2005). Completion of the sequencing of the $B$. pseudomallei genome has revealed potential virulence determinants, and comparative genomics among the genomes of $B$. pseudomallei, $B$. thailandensis and $B$. mallei species has contributed to a better understanding of the organism. Further studies are 
Table 5. Microarray analysis of B. pseudomallei CPS III expression following intraperitoneal inoculation in the hamster model of melioidosis

\begin{tabular}{|llc|}
\hline Gene identifier & \multicolumn{1}{c|}{ Predicted protein function } & Fold change (in vivo vs in vitro) $^{*}$ \\
\hline BPSS1825 & Glycosyltransferase & 1.757155 \\
BPSS1826 & Glycosyltransferase & 0.093565 \\
BPSS1827 & Glucose-6-phosphate isomerase & 2.337866 \\
BPSS1828 & Glycosyltransferase & -0.66607 \\
BPSS1829 & Glycosyltransferase & -0.18061 \\
BPSS1830 & Capsule export, tyrosine-protein kinase & -0.30655 \\
BPSS1831 & Capsule export, outer-membrane protein & 0.725849 \\
BPSS1832 & Transport, tyrosine-protein phosphatase & 1.52665 \\
BPSS1833 & UDP-glucose-6-dehydrogenase & -0.71411 \\
BPSS1834 & Sugar transferase & -0.07963 \\
BPSS1835 & Mannose-1-phosphate guanyltransferase & -0.75075 \\
\hline
\end{tabular}

${ }^{\star}$ Gene expression representative of the liver and lungs of infected hamsters.

ongoing to define the pathogenesis of B. pseudomallei and to identify effective vaccine candidates and diagnostic targets (Cheng \& Currie, 2005; Holden et al., 2004).

Sequence analysis of the genome of B. pseudomallei revealed the presence of four operons possibly involved in CPS biosynthesis. One of these operons (CPS I) corresponded to the previously identified and characterized mannoheptose capsule that has been shown to be responsible for virulence and comprises one of the currently proposed melioidosis and glanders subunit conjugate vaccines (Brett \& Woods, 1996, 2000; Reckseidler et al., 2001; Reckseidler-Zenteno et al., 2005; Warawa \& Woods, 2002). The CPS I capsule cluster is also present in the genome of $B$. mallei, but the complete cluster is not found in the genome of $B$. thailandensis (DeShazer et al., 2001; Nierman et al., 2004; $\mathrm{Yu}$ et al., 2006). This correlates with previous studies that

Table 6. Glycosyl composition of CPS III following analysis by GC/MS

\begin{tabular}{|lcc|}
\hline Glycosyl residue & Mass $(\boldsymbol{\mu g})$ & Mol\% \\
\hline Arabinose & $\mathrm{ND}$ & - \\
Rhamnose & 0.5 & 0.6 \\
Fucose & $\mathrm{ND}$ & - \\
Xylose & 2.3 & 2.9 \\
Glucuronic acid & $\mathrm{ND}$ & - \\
Galacturonic acid & $\mathrm{ND}$ & - \\
Mannose & 6.1 & 6.4 \\
Galactose & 27.8 & 29.4 \\
Glucose & 19.8 & 20.9 \\
$N$-acetylgalactosamine & $\mathrm{ND}$ & - \\
$N$-acetylglucosamine & $\mathrm{ND}$ & - \\
$N$-acetylmannosamine & $\mathrm{ND}$ & - \\
Heptose & 43.9 & 39.8 \\
Total & 100.4 & 100.0 \\
\hline
\end{tabular}

ND, Not determined. have shown that this capsule is produced by $B$. mallei but not by B. thailandensis (Brett et al., 1997; DeShazer et al., 1998, 2001; Reckseidler et al., 2001).

Three other putative capsule operons were identified by sequence analysis, and all of these operons were found to be present in B. pseudomallei and B. thailandensis but not $B$. mallei. As these capsules are found in $B$. thailandensis and $B$. pseudomallei, they may be required for survival in either the host or the environment; however, further studies are required to determine the roles of CPS II and IV.

CPS III, located on chromosome 2, was found to contain 11 genes involved in the biosynthesis of a polysaccharide and was shown to be present in the genomes of $B$. pseudomallei and B. thailandensis but not B. mallei. A mutation in the CPS III cluster did not affect production of CPS I and so it can be concluded that this operon encodes

Table 7. Glycosyl-linkage results of CPS III following GC/MS analysis

\begin{tabular}{|c|c|}
\hline Glycosyl residue & $\begin{array}{c}\text { Percentage } \\
\text { present }\end{array}$ \\
\hline 3-Linked rhamnopyranosyl (3-rha $\left.a_{p}\right)$ & 2.9 \\
\hline Terminally linked mannopyranosyl $\left(\mathrm{t}-\operatorname{man}_{\mathrm{p}}\right)$ & 7.4 \\
\hline Terminally linked glucopyranosyl (t-glc $\left.c_{p}\right)$ & 14.6 \\
\hline Terminally linked galactopyranosyl $\left(\mathrm{t}-\mathrm{gal}_{\mathrm{p}}\right)$ & 2.2 \\
\hline 3-Linked glucopyranosyl $\left(3-\right.$ glc $\left._{\mathrm{p}}\right)$ & 6.0 \\
\hline 2- and 3-linked mannopyranosyl (2- and 3- $\left.\operatorname{man}_{\mathrm{p}}\right)$ & 4.9 \\
\hline Terminally linked hetopyranosyl (t-hep) & 23.2 \\
\hline 3-Linked galactopyranosyl $\left(3-\mathrm{gal}_{\mathrm{p}}\right)$ & 8.1 \\
\hline 4-Linked glucopyranosyl $\left(4-\right.$ glc $\left._{\mathrm{p}}\right)$ & 10.8 \\
\hline 3,4-Linked heptopyranosyl (3,4-hep) & 9.8 \\
\hline 2,6-Linked glucopyranosyl $\left(2,6\right.$-glc $\left.c_{p}\right)$ & 4.2 \\
\hline 3,7-Linked heptopyranosyl (3,7-hep) & 5.9 \\
\hline
\end{tabular}

p, Pyranosyl. 
gene products responsible for the biosynthesis of a separate capsule. CPS III was not found to contribute to the pathogenesis of $B$. pseudomallei. This capsule was not shown to be highly expressed in vivo by microarray analysis and was not required for virulence in the animal model. The CPS III mutant SZ1829, which contains a mutation in the BPSS1829 gene as a result of insertional inactivation, was found to be as virulent in the animal model as wildtype B. pseudomallei. Expression of this capsule was shown to be elevated when incubated in water but suppressed in the presence of NHS. The presence of the CPS III cluster in $B$. pseudomallei and B. thailandensis, both of which can survive for long periods in the environment compared with B. mallei, the increased expression of this capsule in water and the low level of expression of this capsule in vivo suggest that this capsule may contribute to the survival of B. pseudomallei in the environment (Aldhous, 2005; Sanford, 1995; Strauss et al., 1969; Wuthiekanun et al., 1995). The wza gene of this cluster demonstrates homology to the amsK gene of Bacillus cereus, which is involved in amylovoran biosynthesis. Amylovoran has been shown to protect the plant pathogen Erwinia amylovora from water stress (Bereswill \& Geider, 1997).

Previous studies have demonstrated that B. pseudomallei produces three other CPSs in addition to CPS I and these have been structurally characterized. One is an acidic polysaccharide with the structure, [-3)-2-O-acetyl- $\beta$-DGalp-(1-4)- $\alpha$-D-Gal $p-(1-3)-\beta$-D-Gal $p-(1-5)-\beta$-D-KDO $p-(2-]$, which is recognized by patient sera (Nimtz et al., 1997). The other two are a branched 1,4-linked glucan polymer (CP-1a) and a triple-branched heptasaccharide repeating unit composed of rhamnose, mannose, galactose, glucose and glucuronic acid (CP-2) (Kawahara et al., 1998). Combined GC/MS analysis of CPS III revealed that the composition of this capsule demonstrated some similarity to the composition of the previously described capsule $\mathrm{CP}-2$, also being composed of rhamnose, mannose, galactose, glucose and glucuronic acid; however, the proportions of carbohydrate residues were not similar, and the CPS III capsule was also found to contain xylose and not glucuronic acid. In addition, CPS III was determined to be composed primarily of heptose. Therefore, it is evident that the capsule identified in this study is not one of the previously described capsule structures. Some of the previously characterized capsules produced by $B$. pseudomallei have been shown to be produced under unique conditions (Kawahara et al., 1998; Nimtz et al., 1997). Strain variation, differences in expression of the capsules and discrepancies among purification strategies may also explain why a number of capsules have been shown to be produced by this organism. Nevertheless, the genes BPSS1825-BPSS1835 appear to be involved in the biosynthesis of a capsule with this composition. Further analysis by two-dimensional NMR would be required to establish definitively a connection between CPS III and one of the other published structures.

Recent studies have also focused on the presence of these capsule clusters in B. pseudomallei. Sarkar-Tyson et al.
(2007) identified two polysaccharide clusters, one of which corresponded to the CPS III presented in this paper, but the authors identified this cluster as type IV O-antigenic polysaccharide, which was found to be involved in virulence in a mouse model. However, a mutant in this polysaccharide did not demonstrate any difference in hydrophobicity compared with wild-type, indicating that this polysaccharide does not contribute to making the cell surface more hydrophobic, which is an advantageous characteristic for some pathogenic bacteria. The differences in virulence compared with the current work can be attributed to the use of different animal models; however, all other data seem to indicate that this capsule is not required for virulence.

B. pseudomallei is an environmental saprophyte often found in soil and stagnant water, and the incidence of infection is high in rice farmers in South-East Asia (Aldhous, 2005; Leelarasamee \& Bovornkitti, 1989). This organism harbours a large genome, which explains its ability to survive for long periods of time in the environment, as well as its ability to exist as a significant pathogen in both humans and animals. The presence of multiple polysaccharide clusters in the genome and the production of multiple capsule structures under differing conditions may contribute to the ability of this organism to adapt to a variety of conditions. As demonstrated in this study, capsule expression is dependent on the particular environment, which indicates that $B$. pseudomallei produces these capsules to promote a survival advantage either in the host or in the environment. Further studies aimed at characterizing the capsules of $B$. pseudomallei will be beneficial to understand the pathogenesis of this organism and to advance further vaccine development.

\section{ACKNOWLEDGEMENTS}

This work was funded by the Canadian Institutes of Health (with a research grant (MOP-36343) to D. E. W. and by a Research Incentive grant from Athabasca University to S. L. R.-Z. Carbohydrate analysis was conducted by the Complex Carbohydrate Research Center at the University of Georgia (Athens, GA, USA) and this was supported in part by the Department of Energy-funded (DE-FG09-93ER-20097) Center for Plant and Microbial Complex Carbohydrates (Athens, GA, USA). We wish to thank the staff at the Southern Alberta Microarray Facilities (Calgary, AB, Canada) for technical support. We also thank Marina Tom for excellent technical assistance.

\section{REFERENCES}

Aldhous, P. (2005). Tropical medicine: melioidosis? Never heard of it.... Nature 434, 692-693.

Atkins, T., Prior, R., Mack, K., Russel, P., Nelson, M., Prior, J., Oyston, P. C., Dougan, G. \& Titball, R. W. (2002). Characterization of an acapsular mutant of Burkholderia pseudomallei identified by signature tagged mutagenesis. J Med Microbiol 51, 539-547.

Bereswill, S. \& Geider, K. (1997). Characterization of the $r c s B$ gene from Erwinia amylovora and its influence on exopolysaccharide synthesis and virulence of the fire blight pathogen. J Bacteriol 179, 1354-1361. 
Boulnois, G. J. \& Roberts, I. S. (1990). Genetics of capsular polysaccharide production in bacteria. Curr Top Microbiol Immunol 150, 1-18.

Boyer, H. W. \& Roulland-Dussoix, D. (1969). A complementation analysis of the restriction and modification of DNA in Escherichia coli. J Mol Biol 41, 459-472.

Brett, P. J. \& Woods, D. E. (1996). Structural and immunological characterization of Burkholderia pseudomallei O-polysaccharideflagellin protein conjugates. Infect Immun 64, 2824-2828.

Brett, P. J. \& Woods, D. E. (2000). Pathogenesis of and immunity to melioidosis. Acta Trop 74, 201-210.

Brett, P. J., DeShazer, D. \& Woods, D. E. (1997). Characterization of Burkholderia pseudomallei and Burkholderia pseudomallei-like strains. Epidemiol Infect 118, 137-148.

Brett, P. J., DeShazer, D. \& Woods, D. E. (1998). Burkholderia thailandensis sp. nov., description of a Burkholderia pseudomallei-like species. Int J Syst Bacteriol 48, 317-320.

Bryan, L. E., Wong, S., Woods, D. E., Dance, D. A. \& Chaowagul, W. (1994). Passive protection of diabetic rats with antisera specific for the polysaccharide portion of the lipopolysaccharide isolated from Pseudomonas pseudomallei. Can J Infect Dis 5, 170-178.

Cheng, A. C. \& Currie, B. J. (2005). Melioidosis: epidemiology, pathophysiology, and management. Clin Microbiol Rev 18, 383416.

Currie, B. J. \& Jacups, S. P. (2003). Intensity of rainfall and severity of melioidosis, Australia. Emerg Infect Dis 9, 1538-1542.

Currie, B. J., Fisher, D. A., Howard, D. M., Burrow, J. N., Selvanayagam, S., Snelling, P. L., Anstey, N. M. \& Mayo, M. J. (2000a). The epidemiology of melioidosis in Australia and Papua New Guinea. Acta Trop 74, 121-127.

Currie, B. J., Fisher, D. A., Anstey, N. M. \& Jacups, S. P. (2000b). Melioidosis: acute and chronic disease, relapse and re-activation. Trans R Soc Trop Med Hyg 94, 301-304.

Currie, B. J., Jacups, S. P., Cheng, A. C., Fisher, D. A., Anstey, N. M., Huffam, S. E. \& Krause, V. L. (2004). Melioidosis epidemiology and risk factors from a prospective whole-population study in northern Australia. Trop Med Int Health 9, 1167-1174.

Dance, D. A. B. (1991). Melioidosis: the tip of the iceberg? Clin Microbiol Rev 4, 52-60.

de Weert, S., Vermeiren, H., Mulders, I. H., Kuiper, I., Hendrickx, N., Bloemberg, G. V., Vanderleyden, J., De Mot, R. \& Lugtenberg, B. J. (2002). Flagella-driven chemotaxis towards exudate components is an important trait for tomato root colonization by Pseudomonas fluorescens. Mol Plant Microbe Interact 15, 1173-1180.

DeShazer, D. \& Woods, D. E. (1999). Animal models of melioidosis. In Handbook of Animal Models of Infection, pp. 199-203. Edited by O. Zak \& M. Sande. London: Academic Press.

DeShazer, D., Brett, P. J., Carylon, R. \& Woods, D. E. (1997). Mutagenesis of Burkholderia pseudomallei with Tn5-OT182: isolation of motility mutants and molecular characterization of the flagellin structural gene. J Bacteriol 179, 2116-2125.

DeShazer, D., Brett, P. J. \& Woods, D. E. (1998). The type II Oantigenic polysaccharide moiety of Burkholderia pseudomallei lipopolysaccharide is required for serum resistance and virulence. Mol Microbiol 30, 1081-1100

DeShazer, D., Waag, D. M., Fritz, D. L. \& Woods, D. E. (2001). Identification of a Burkholderia mallei polysaccharide gene cluster by subtractive hybridization and demonstration that the encoded capsule is an essential virulence determinant. Microb Pathog 30, 253-269.

Dong, C., Beis, K., Nesper, J., Brunkan-Lamontagne, A. L., Clarke, B. R., Whitfield, C. \& Naismith, J. H. (2006). Wza the translocon for $E$ coli capsular polysaccharides defines a new class of membrane protein. Nature 444, 226-229.

Figurski, D. H. \& Helsinki, D. R. (1979). Replication of an origincontaining derivative of plasmid RK2 dependent on a plasmid function provided in trans. Proc Natl Acad Sci U S A 76, 1648-1652.

Grangeasse, C., Obadia, B., Mijakovic, I., Deutscher, J., Cozzone, A. J. \& Doublet, P. (2003). Autophosphorylation of the Escherichia coli protein kinase Wzc regulates tyrosine phosphorylation of Ugd, a UDP-glucose dehydrogenase. J Biol Chem 278, 39323-39329.

Holden, M. T., Titball, R. W., Peacock, S. J., Cerdeño-Tárraga, A. M., Atkins, T., Crossman, L. C., Pitt, T., Churcher, C., Mungall, K. \& other authors (2004). Genomic plasticity of the causative agent of melioidosis, Burkholderia pseudomallei. Proc Natl Acad Sci U S A 101, 14240-14245.

Jensen, S. O. \& Reeves, P. R. (2001). Molecular evolution of the GDP-mannose pathway genes ( $\operatorname{manB}$ and $\operatorname{manC}$ ) in Salmonella enterica. Microbiology 147, 599-610.

Kawahara, K., Dejsirilert, S. \& Ezaki, T. (1998). Characterization of three capsular polysacharides produced by Burkholderia pseudomallei. FEMS Microbiol Lett 169, 283-287.

Kereszt, A., Kiss, E., Reuhs, B. L., Carlson, R. W., Kondorosi, A. \& Putnoky, P. (1998). Novel $r k p$ gene clusters of Sinorhizobium meliloti involved in capsular polysaccharide production and invasion of the symbiotic nodule: the $r k p K$ gene encodes a UDP-glucose dehydrogenase. J Bacteriol 180, 5426-5431.

Leelarasamee, A. \& Bovornkitti, S. (1989). Melioidosis: review and update. Rev Infect Dis 11, 413-425.

Lescop, E., Hu, Y., Xu, H., Hu, W., Chen, J., Xia, B. \& Jin, C. (2006). The solution structure of Escherichia coli Wzb reveals a novel substrate recognition mechanism of prokaryotic low molecular weight proteintyrosine phosphatases. J Biol Chem 281, 19570-19577.

Merkle, R. K. \& Poppe, I. (1994). Carbohydrate composition analysis of glycoconjugates by gas-liquid chromatography/mass spectrometry. Methods Enzymol 230, 1-15.

Moore, R. A., DeShazer, D., Reckseidler, S., Weissman, A. \& Woods, D. E. (1999). Efflux-mediated aminoglycoside and macrolide resistance in Burkholderia pseudomallei. Antimicrob Agents Chemother 43, 465-470.

Moore, R. A., Reckseidler-Zenteno, S., Kim, H., Nierman, W., Yu, Y., Tuanyok, A., Warawa, J., DeShazer, D. \& Woods, D. E. (2004). The contribution of gene loss to the pathogenic evolution of Burkholderia pseudomallei and Burkholderia mallei. Infect Immun 72, 4172-4187.

Moreira, L. M., Videira, P. A., Sousa, S. A., Leitao, J. H., Cunha, M. V. \& Sa-Correia, I. (2003). Identification and physical organization of the gene cluster involved in the biosynthesis of Burkholderia cepacia complex exopolysaccharide. Biochem Biophys Res Commun 312, 323-333.

Ngauy, V., Lemeshev, Y., Sadkowski, L. \& Crawford, G. (2005). Cutaneous melioidosis in a man who was taken as a prisoner of war by the Japanese during World War II. J Clin Microbiol 43, 970-972.

Nierman, W. C., DeShazer, D., Kim, H. S., Tettelin, H., Nelson, K. E., Feldblyum, T., Ulrich, R. L., Ronning, C. M., Brinkac, L. M. \& other authors (2004). Structural flexibility in the Burkholderia mallei genome. Proc Natl Acad Sci U S A 101, 14246-14251.

Nimtz, M., Wray, V., Domke, T., Brenneke, B., Haussler, S. \& Steinmetz, I. (1997). Structure of an acidic exopolysaccharide of Burkholderia pseudomallei. Eur J Biochem 250, 608-616.

Perry, M. B., MacLean, L. L., Schollaardt, T., Bryan, L. E. \& Ho, M. (1995). Structural characterization of the lipopolysaccharide $O$ antigens of Burkholderia pseudomallei. Infect Immun 63, 3348-3352.

Raymond, C. K., Sims, E. H., Kas, A., Spencer, D. H., Kutyavin, T. V., Ivey, R. G., Zhou, Y., Kaul, R., Clendenning, J. B. \& Olson, M. V. 
(2002). Genetic variation at the O-antigen biosynthetic locus in Pseudomonas aeruginosa. J Bacteriol 184, 3614-3622.

Reckseidler, S. L., DeShazer, D., Sokol, P. A. \& Woods, D. E. (2001). Detection of bacterial virulence genes by subtractive hybridization: identification of capsular polysaccharide of Burkholderia pseudomallei as a major virulence determinant. Infect Immun 69, 34-44.

Reckseidler-Zenteno, S. L., DeVinney, R. \& Woods, D. E. (2005). The capsular polysaccharide of Burkholderia pseudomallei contributes to survival in serum by reducing complement factor C3b deposition. Infect Immun 73, 1106-1115.

Regué, M., Izquierdo, L., Fresno, S., Piqué, N., Corsaro, M. M., Naldi, T., De Castro, C., Waidelich, D., Merino, S. \& Tomás, J. M. (2005). A second outer-core region in Klebsiella pneumoniae lipopolysaccharide. J Bacteriol 187, 4198-4206.

Sanford, J. P. (1995). Pseudomonas species (including melioidosis and glanders). In Principles and Practice of Infectious Diseases, pp. 2003-2009. Edited by G. L. Mandell, R. G., Jr \& J. E. Bennett. New York: Churchill Livingstone.

Sarkar-Tyson, M., Thwaite, J. E., Harding, S. V., Smither, S. J., Oyston, P. C. F., Atkins, T. P. \& Titball, R. W. (2007). Polysaccharides and virulence of Burkholderia pseudomallei. J Med Microbiol 56, 10051010.

Stevenson, G., Lan, R. \& Reeves, P. R. (2000). The colanic gene cluster of Salmonella enterica has a complex history. FEMS Microbiol Lett 191, 11-16.

Strauss, J. M., Groves, M. G., Mariappan, M. \& Ellison, D. W. (1969). Melioidosis in Malaysia. II. Distribution of Pseudomonas pseudomallei in soil and surface water. Am J Trop Med Hyg 18, 698-702.

Tuanyok, A., Kim, H. S., Nierman, W. C., Yu, Y., Dunbar, J., Moore, R. A., Baker, P., Tom, M., Ling, J. M. L. \& Woods, D. E. (2005). Genome-wide expression analysis of iron regulation in Burkholderia pseudomallei and Burkholderia mallei using DNA microarrays. FEMS Microbiol Lett 252, 327-335.
Tuanyok, A., Tom, M., Dunbar, J. \& Woods, D. E. (2006). Genomewide expression analysis of Burkholderia pseudomallei infection in a hamster model of acute melioidosis. Infect Immun 74, 5465-5476.

Wang, Y., Lechno-Yossef, S., Gong, Y., Fan, Q., Wolk, C. P. \& Xu, X. (2007). Predicted glycosyl transferase genes located outside the HEP island are required for formation of heterocyst envelope polysaccharide in Anabaena sp. strain PCC 7120. J Bacteriol 189, 5372-5378.

Warawa, J. \& Woods, D. E. (2002). Melioidosis vaccines. Expert Rev Vaccines 1, 477-482.

Westphal, O. \& Jann, K. (1965). Extraction with phenol-water and further applications of the procedure. Methods Carbohydr Chem 25, 83-91.

White, N. J., Dance, D. A. B., Chaowagul, W., Wattanagoon, Y., Wuthiekanun, V. \& Pitakwatchara, N. (1989). Halving of mortality of severe melioidosis by ceftazadime. Lancet 2, 697-701.

Whitmore, A. \& Krishnaswami, C. S. (1912). An account of the discovery of a hitherto undescribed infective disease occurring among the population of Rangoon. Ind Med Gaz 47, 262-267.

Wuthiekanun, V., Smith, M. D., Dance, D. A. \& White, N. J. (1995). Isolation of Pseudomonas pseudomallei from soil in north-eastern Thailand. Trans R Soc Trop Med Hyg 89, 41-43.

Yee, K. C., Lee, M. K., Chua, C. T. \& Puthucheary, S. D. (1988). Melioidosis, the great mimicker: a report of 10 cases from Malaysia. J Trop Med Hyg 91, 249-254.

York, W. S., Darvill, A. G., McNeil, M., Stevenson, T. T. \& Albersheim, P. (1986). Isolation and characterization of plant cell walls and cell wall components. Methods Enzymol 118, 3-40.

Yu, Y., Kim, H. S., Chua, H. H., Lin, C. H., Sim, S. H., Lin, D., Derr, A., Engels, R., DeShazer, D. \& other authors (2006). Genomic patterns of pathogen evolution revealed by comparison of Burkholderia pseudomallei, the causative agent of melioidosis, to avirulent Burkholderia thailandensis. BMC Microbiol 6, 46. 